\title{
M axillary sinus floor augmentation with vegetal hydroxyapatite "versus" demineralized bovine bone: A randomized clinical study with a split-mouth design
}

\author{
Giuliano G arlini, M arco Redemagni, Elena Canciani ${ }^{1}$, Claudia Dellavia $^{1}$
}

\section{ABSTRACT}

Purpose: The objective of this paper was to compare histologically and histomorphometrically a hydroxyapatite originated by algae (Algipore) versus demineralized bovine bone (Bio-Oss Geistlich Pharma, Wolhusen, Switzerland) utilised as bone substitutes in maxillary sinus floor elevation with a split-mouth design.

Materials and Methods: Five healthy patients underwent a bilateral maxillary sinus floor elevation procedure under local anesthesia. In each case, residual posterior maxillary bone height was between $2 \mathrm{~mm}$ and $5 \mathrm{~mm}$. The original bone was augmented with a split-mouth design with $100 \%$ Algipore on the test side and $100 \%$ Bio-Oss on the contralateral control side. After a healing period of 6-8 months during the re-opening surgery biopsies were retrieved and Xive Implants (Dentsply Implants, Mannheim, Germany) were placed.

Results: At microscopic level both Bio-Oss and Algipore blocks resulted well osseointegrated, without inflammatory infiltrate, with an high level of mineralization, without gap between the bone and biomaterial interfaces that resulted indistinguishable. A close contact between the two faces was observed without the presence of slits. Histomorphometrical analysis showed that, on average, the percentage of medullary space was higher for the Bio-Oss compared with Algipore $138.61 \% \pm 8.90 \%$ vs. $29.23 \% \pm 7.89 \%)$. In contrast, the mean value of residual particles of biomaterials was higher in Algipore than in Bio-Oss specimens ( $42.86 \% \pm 18.61 \%$ vs. $22.30 \% \pm 6.40 \%$ respectively).

Conclusions: The data confirmed that sinus lift carried out with Algipore performed in a similar way of that carried out with Bio-Oss and that this material is safe, predictable and without invasiveness.

KEY WORDS: Bone substitutes, demineralized bovine bone, sinus augmentation, vegetable hydroxyapatite

\section{INTRO DUCTION}

Lack of sufficient bone height in the posterior maxilla precluded implant placement in this area in the past.

Private Office, ${ }^{1}$ Department of Biomedical, Surgical and Dental Sciences, Università Degli Studi di Milano, Milan, Italy

Address for correspondence: Dr. Giuliano Garlini,

Via Tajani 10, Milan, Italy.

E-mail: giuliano@studiochierichettigarlini.it

\begin{tabular}{|l|l|}
\hline \multicolumn{2}{|c|}{ Access this article online } \\
\hline Quick Response Code: & Website: \\
\hline & www.jdionline.org \\
\hline & \\
\hline
\end{tabular}

After the experimental studies published by Boyne and James, and Tatum ${ }^{[1,2]}$ regarding grafts in the maxillary sinus, a number of new procedures and studies have documented the use of different implants and grafting materials. To allow implant placement in the posterior part of the maxilla, sinus floor augmentation surgery has become a routine procedure ${ }^{[3-5]}$ that results in an implant survival rate of over $90 \%$ for $3-5$ years. $^{[6-8]}$ Autogenous bone is considered the gold standard reconstructive material in bone augmentation for osseoproliferative, osseoinductive, and osseoconductive properties; however not all patients are suitable to undergo complex surgeries in intraoral (chin and retromolar areas) or extraoral donor site, due to potential risks of morbidity and complaints. ${ }^{[9]}$ On the other hand, when taken from intraoral sites, bone cannot often provide the large quantity of material needed for augmentation. Hence, 
there is the need for a bone regenerative material that is biocompatible, resorbable, and easily and quickly replaceable by bone tissue. Many bone substitutes have been tried in order to find a good alternative to autografts, but even the best among the bone substitutes is only osteoconductive (e.g. hydroxyapatite, allografts, xenografts, and alloplastic materials). These materials are suitable for sinus augmentation procedures since they are available in the needed quantity and maintain the original volume during the substitution process. ${ }^{[10,11]}$ Actually the most frequently used bone substitute in sinus augmentation is demineralized bovine bone (DBB), either alone or in combination with autogenous bone. ${ }^{[5,12,13]}$ It must be noted that allografts and xenografts used as alternatives to autografts have a potential for disease transmission ${ }^{[14]}$ while alloplasts have not risks. At this purpose, some alloplastic biomaterial are used in the clinical practice to reduce biological risks. Algipore is a granulate material manufactured from calcifying marine algae (Corallina officinalis). ${ }^{[15]}$ Biomaterial processing involves pyrolytical segmentation of the native algae and hydrothermal transformation of the calcium carbonate into fluorohydroxyapatite (FHA). This process preserves the porosity of the algae ${ }^{[16]}$ and the organic components are completely removed. ${ }^{[17]}$

The objective of this paper was to compare histologically, and histomorphometrically a vegetable originated hydroxyapatite (Algipore) with DBB (Bio-Oss) utilised as bone substitutes alone in sinus floor elevation in a split-mouth design.

\section{MATERIALS AND METHODS}

This study was carried out on a group of 5 patients ( 2 men and 3 women) with a bilateral defect of dentition in the posterior maxilla.

All the patients had residual sinus floor of $<5 \mathrm{~mm}$ in height and at least $5 \mathrm{~mm}$ in width in both sides.

To be considered eligible for the study, the following general inclusion criteria needed to be met:

- Implant therapy was required bilaterally in the posterior maxilla to restore masticatory function

- There was the absence of sinus infection of the Schneiderian Membrane

- Patients had to be medically fit and healthy, and able to undergo oral surgical procedures under local anaesthesia

- Patients with chronic periodontitis had to have been treated first.

Light smokers ( $<10$ cigarettes/die) were not excluded, but were given appropriate warming about the increased risk of surgical complications.
Patients were informed about their participation in the study according to the Helsinki declaration of 2008.

On one side the sinus lift procedure was performed using demineralised bovine bone (Bio-Oss Geistlich Pharma, Wolhusen, Switzerland), while on the other side the sinus lift procedures was performed using a phytogenic bone substitute (Algipore, Dentsply Implants, Mannheim, Germany).

Algipore was observed at three-dimensional scanning electron microscopy (JSM 6310, Jeol Ltd., Tokyo, Japan) provides valuable information about the structural architecture of particles. The particles contain a pore system (mean diameter of pores is $10 \mu \mathrm{m}$ ) that is periodically regulated (mean interval $30 \mu \mathrm{m}$ ) and interconnectively microperforated (mean diameter of perforations $1 \mu \mathrm{m}$ ). Every pore is limited by one layer of small FHA crystallites with a size of $25-35 \mathrm{~nm}$. Algipore granules range from $0.3 \mathrm{~mm}$ to $2 \mathrm{~mm}$ and demonstrate a bone-equivalent microarchitecture and their chemical composition is pre inorganic calcium phosphate. ${ }^{[15,16]}$ Algipore has a large surface area $\left(50 \mathrm{~m}^{2} / \mathrm{g}\right)$ and a specific pore volume averages $0.93 \mathrm{~cm}^{3} / \mathrm{g}^{[15]}$ and its elevated interconnected microporosity should help the neovascularization and bone ingrowth. ${ }^{[18]}$

Bio-Oss is a bone substitute of bovine origin frequently used for various augmentation procedures, either alone or in combination with autogenous bone. ${ }^{[19,20]}$

\section{Surgery}

The surgical procedures were performed under local anaesthesia by two operators skilled in oral surgery. The sinus lift was carried out using the window technique. ${ }^{[21]}$ A crestal incision was performed, and a full-thickness mucoperiosteal flap was elevated to expose the facial wall of the maxillary sinus. A longitudinal osteotomy was prepared for latero-basal approach to the maxillary sinus using a conventional handpiece with a round bur. Sinus membrane elevators were used to dissect the Schneiderian membrane from the alveolar recessus. In two cases the residual alveolar height were $<2 \mathrm{~mm}$, with no possibility of implant insertion, while, in the other three cases, the residual alveolar crest was $>3 \mathrm{~mm}$ so some Xive implants (Dentsply Implants, Mannehim, Germany) were inserted [Figure 1]. After placement of the graft into both alveolar recessus, the lateral wall osteotomy site was obturated with a resorbable membrane (Bioguide, Geistlich Pharma, Wolhusen, Switzerland) to ensure graft containment and prevent soft tissue invagination. The mucoperiosteal flap was then repositioned and sutured with polypropilene 5-0 (Butterfly Italia, Cavenago, Italy). A postoperative oral antibiotic regimen of $2 \mathrm{~g}$ Amoxycillin (Augmentin, GlaxoSmithKline, Verona, Italy) daily in two divided doses for 5 days was prescribed. 
During the rehabilitation procedures, trephine specimens were retrieved for histological analysis.

\section{Sample preparation}

Specimens were obtained from each surgical site by a 3-mm inner diameter trephine bur. The biopsies were processed for ground sections according with the method of Donath and Breuner. ${ }^{[22]}$ The grafted biopsies were fixed in $10 \%$ formalin/0.1 M phosphate buffer saline solution ( $\mathrm{pH}$ 7.4) at room temperature, dehydrated by increasing ethanol concentrations with agitation and vacuum and resin-embedded in Kulzer Technovit 7200 VLC (Bio-Optica, Milano Italy) after 1 month [Figures 2 and 3]. The cores were sliced longitudinally and subsequently reduced by microgrinding and polishing to a thickness of $80 \mu \mathrm{m}$ (Micromet and LS2, Remet, Bologna, Italy). The sections were mounted on plastic slides, stained with Toluidine Blue/Pyronin Y (Sigma-Aldrich, St. Louis, Mo, USA).

\section{Histological examination}

Histological analysis was focused on new bone formation and biomaterial remodelling/replacement. Two central sections for each specimen were used for analysis.

The staining shows clearly the difference between mature bone (stained in brown/yellow) and the bone in different stages of mineralization (in scale of blue); it is possible to observe biomaterial with high mineralization level stained in light brown.

The ground sections were observed using Nikon light microscope (Eclipse E600, Nikon, Tokyo, Japan) equipped with a calibrated digital camera (DXM 1200, Nikon).

Histomorphometrical measurements of the tissue fractions (residual Bio-Oss/Algipore graft, newly formed bone, medullary spaces and/or connective tissue, respectively) in the augmented area were performed using a standard point-counting technique on photographs at a total magnification of $\times 100$. This technique uses a grid where test points (intersection points) falling on the tissue of interest are counted, and the results are expressed as a percentage of the total test points. Stereological method allows to obtain three-dimensional data from two-dimensional sections based on the principles of geometric probability (Delesse formula).

All histological and histomorphometrical analyses were performed at the Department of Biomedical, Surgical and Dental Sciences, Università degli Studi di Milano.

\section{Statistical analysis}

For each measure, two slides were analyzed from each sample and the mean value was computed.

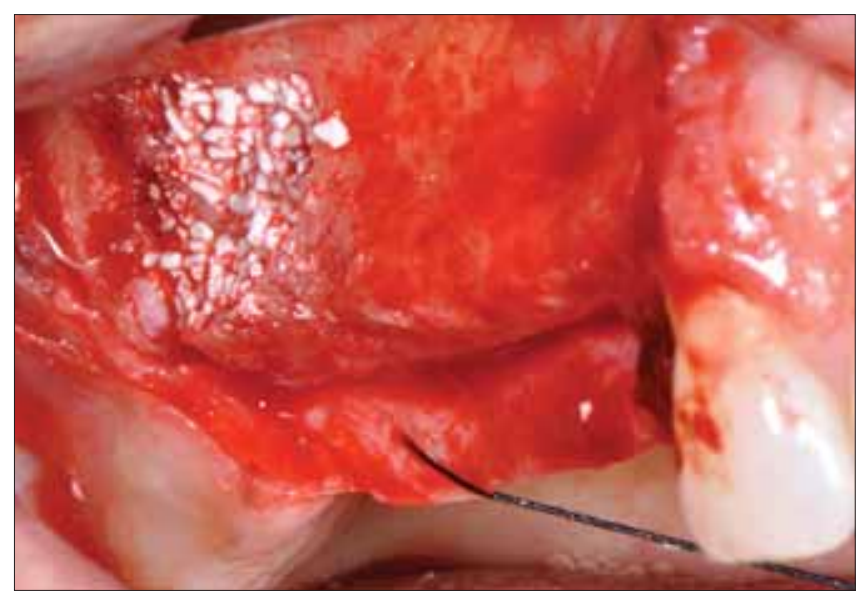

Figure 1: One stage sinus lift with Algipore particles

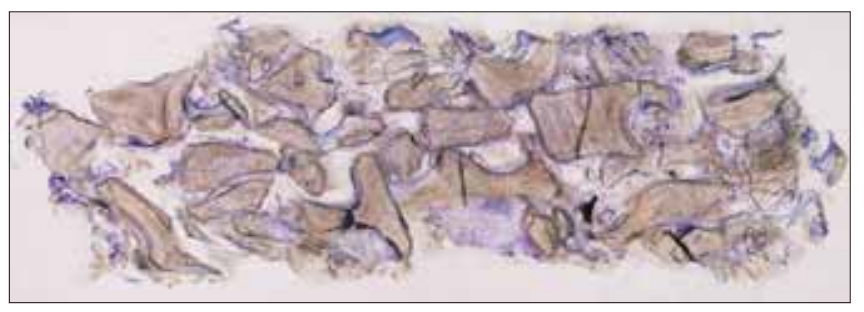

Figure 2: O verview of a specimen grafted with Bio-O ss. Light microscope, total magnification $\times 20$, Toluidine Blue/Pyronin $Y$

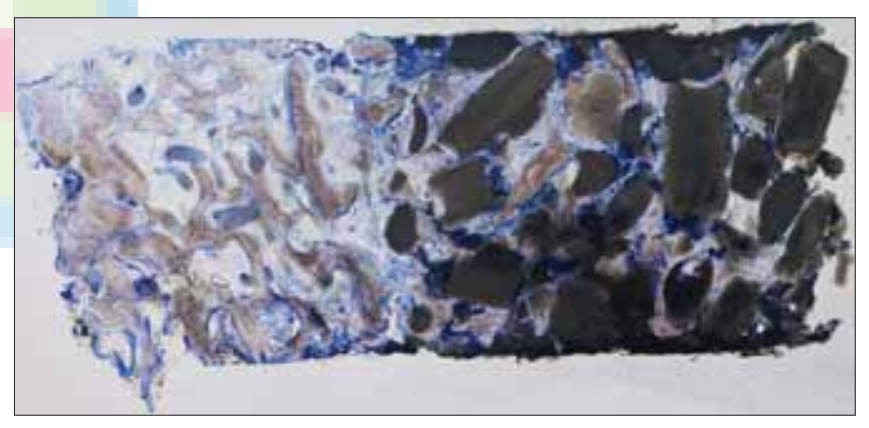

Figure 3: O verview of a specimen grafted with Algipore. Light microscope, total magnification $\times 20$, Toluidine Blue/Pyronin $Y$

For all measurements mean and standard deviation were computed in the two groups of samples (Bio-Oss and Algipore).

The two groups were then compared using a Wilcoxon signed-rank test for paired samples (level of significance, $P<0.05)$.

\section{RESULTS}

Five patients were recruited for this study (age range from 42 years to 64 years, average 57).

No complications occurred during the postoperative period. 
After 6-8 months of healing, a total of 14 Xive implants (11 or $13 \mathrm{~mm}$ in length and 3.8 or $4.5 \mathrm{~mm}$ in diameter, Dentsply Implants, Mannheim, Germany) were inserted in the lifted sinuses [Table 1]. During implant placement, 10 specimens (two per patient in a total of five patients) were retrieved for histological analysis (5 with Bio-Oss graft and 5 with Algipore graft) using a water-cooled $3 \mathrm{~mm}$ wide trephine drill.

The samples were analyzed to evaluate the regenerated area counting the proportions of medullary spaces, new bone and residual biomaterial in each specimen reported in Table 2.

In both cases inflammatory infiltrate was not presented, bacteria was not detected and numerous biomaterial blocks appeared well osseointegrated [Figures 2-9].

Bio-Oss particles appeared surrounded and well osteointegrated in regenerated lamellar bone [Figure 2]; at higher magnifications the borders between bone and biomaterial seemed close together without gaps [Figures 4 and 5]. At a deeper observation, all samples appeared regularly rich in cells and vessels in medullary spaces surrounding the biomaterial.

\begin{tabular}{|c|c|c|c|c|}
\hline $\mathbf{n}$ & Patient & $\begin{array}{l}\text { Biomaterial } \\
\text { type }\end{array}$ & $\begin{array}{c}\text { Time } \\
\text { (months) }\end{array}$ & $\begin{array}{c}\text { Number of } \\
\text { implants }\end{array}$ \\
\hline \multirow[t]{2}{*}{1} & Female & Bio-Oss & 6 & 1 \\
\hline & 65 years & Algipore & 6 & 2 \\
\hline \multirow[t]{2}{*}{2} & Male & Bio-Oss & 6 & 1 \\
\hline & 69 years & Algipore & 8 & 1 \\
\hline \multirow[t]{2}{*}{3} & Male & Bio-Oss & 8 & 2 \\
\hline & 38 years & Algipore & 7 & 1 \\
\hline \multirow[t]{2}{*}{4} & Female & Bio-Oss & 6 & 1 \\
\hline & 70 years & Algipore & 6 & 2 \\
\hline \multirow[t]{2}{*}{5} & Female & Bio-Oss & 7 & 2 \\
\hline & 61 years & Algipore & 7 & 1 \\
\hline
\end{tabular}

The samples characterized by Algipore graft have maintained similar features to the Bio-Oss samples. Algipore blocks appeared surrounded by lamellar bone [Figures 3 and 6], and at higher magnification, blocks were joined by bone bridge connections [Figures 6 and 7]. The close contact between the two blocks was observed without the presence of slits [Figure 7]. In the specimens bone was in different grade of mineralization, with the normal microstructure, rich in osteocytic lacunae and remodeling lines [Figure 8]. Unmineralized areas were widespread on all samples and were characterized by a significant quantity of collagen matrix where many cells were present. Different kinds of cells were detected into the marrow spaces such as adypocytes, stromal cells near new blood vessels [Figures 8 and 9]; furthermore around the grafted blocks, several osteoblasts and osteoclasts were seen [Figure 9]. Moreover, some cells were found into the Algipore pores [Figures 7 and 9].

Histomorphometric results showed different tissue fractions between two biomaterials [Table 2]. On

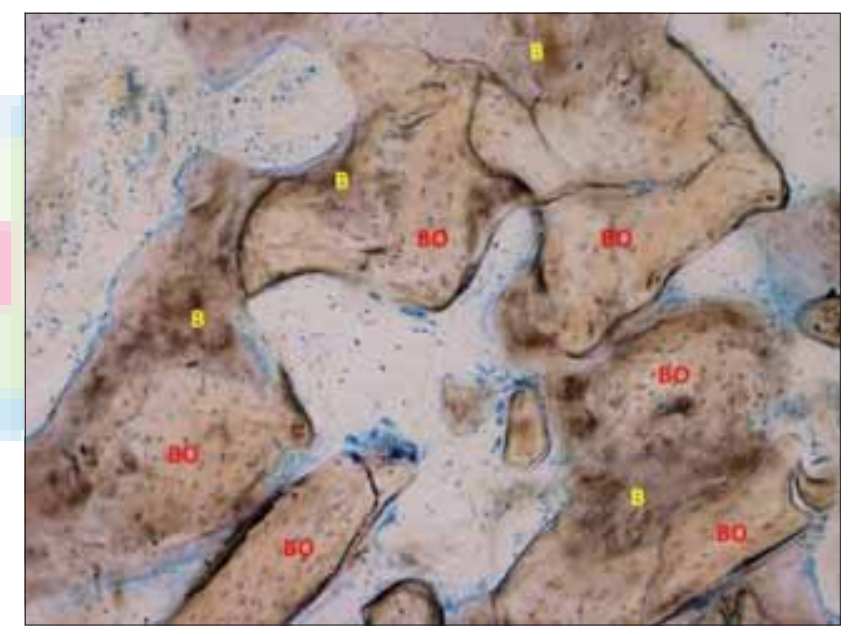

Figure 4: Bio-O ss (BO). N umerous biomaterial blocks resulted well osseointegrated and surrounded by lamellar bone $(B)$ with a high level of mineralization. Inflammatory infiltrate was not observed. Light microscope, total magnification $\times 100$, Toluidine Blue/Pyronin Y

\begin{tabular}{|c|c|c|c|c|c|}
\hline n & Patient & Biomaterial type & Medullary space & Residual biomaterial & Regenerated bone \\
\hline \multirow[t]{2}{*}{1} & Female & Bio-Oss & 48.06 & 25.58 & 26.36 \\
\hline & 65 years & Algipore & 20.34 & 49.15 & 30.51 \\
\hline \multirow[t]{2}{*}{2} & Male & Bio-Oss & 33.33 & 25.31 & 41.36 \\
\hline & 69 years & Algipore & 41.95 & 12.64 & 45.40 \\
\hline \multirow[t]{2}{*}{3} & Male & Bio-Oss & 48.37 & 15.76 & 35.87 \\
\hline & 38 years & Algipore & 29.30 & 45.86 & 24.84 \\
\hline \multirow[t]{2}{*}{4} & Female & Bio-Oss & 29.73 & 15.32 & 54.95 \\
\hline & 70 years & Algipore & 27.64 & 43.22 & 29.15 \\
\hline \multirow[t]{2}{*}{5} & Female & Bio-Oss & 33.56 & 29.53 & 36.91 \\
\hline & 61 years & Algipore & 26.90 & 63.45 & 9.64 \\
\hline
\end{tabular}




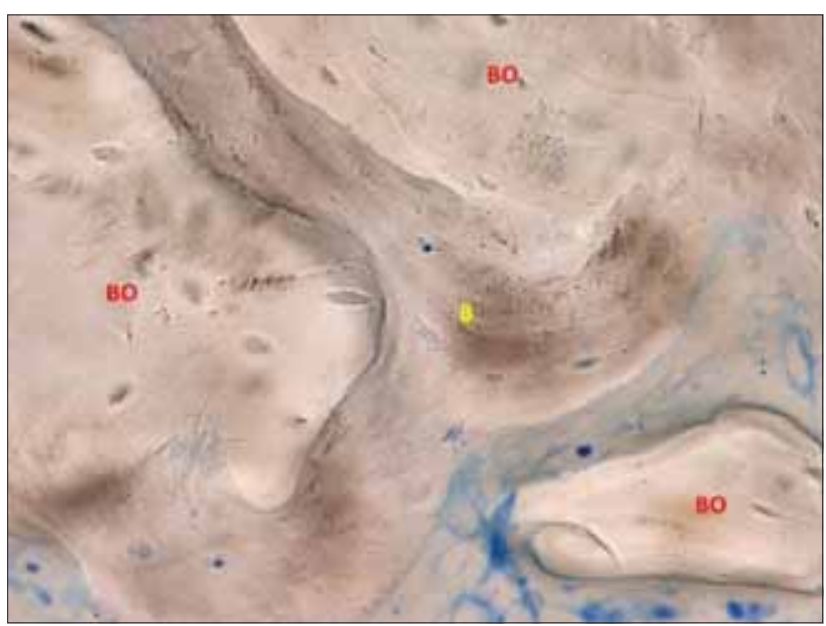

Figure 5: Bio-O ss (BO ). At high magnification, Bio-O ss blocks were surrounded by bone (B) with high level of mineralization, the borders between the two tissues were indistinguishable. Light microscope, total magnification $\times 400$, Toluidine Blue/Pyronin $Y$

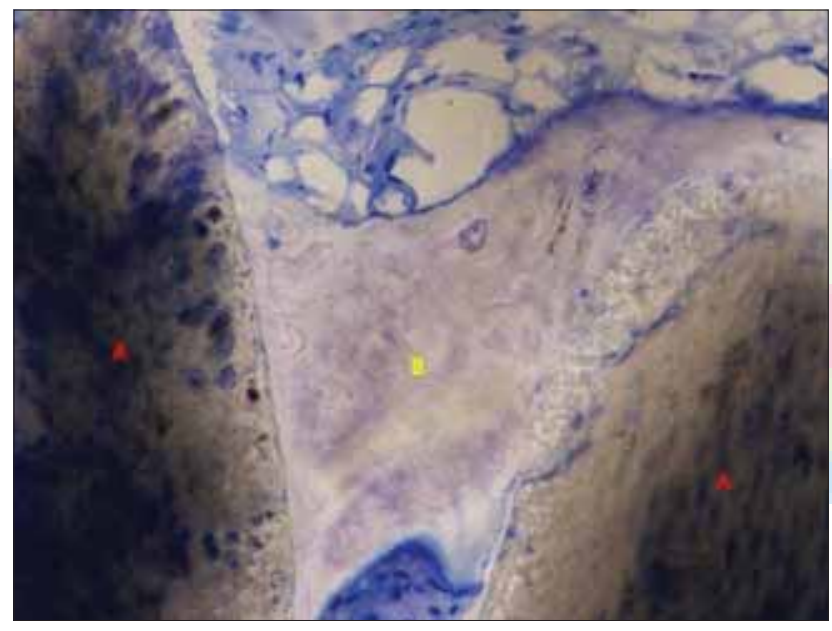

Figure 7: Algipore (A). A higher magnification some Algipore blocks were joined by bone connections $(B)$. The close contact between the two blocks was observed without the presence of slits. Light microscope, total magnification $\times 400$, Toluidine Blue/Pyronin $Y$

average, the percentage of medullary spaces was larger in Bio-Oss than in Algipore samples (38.61\% $\pm 8.90 \%$ vs. $29.23 \% \pm 7.89 \%$ ); the mean value of residual particles of biomaterial was larger in Algipore than in Bio-Oss specimens $(42.86 \% \pm 18.61 \%$ vs. $22.30 \% \pm 6.40 \%$ respectively) and consequently the new bone formation percentage was larger in Bio-Oss samples $(39.09 \%$ $\pm 10.42 \%$ for Bio-Oss and $27.91 \pm 12.82$ for Algipore).

At statistical analysis, no significant differences in terms of medullary spaces, new bone formation and residual biomaterial were found between the two groups (Wilcoxon signed-rank test for paired data, $\mathrm{P}>0.05)$.

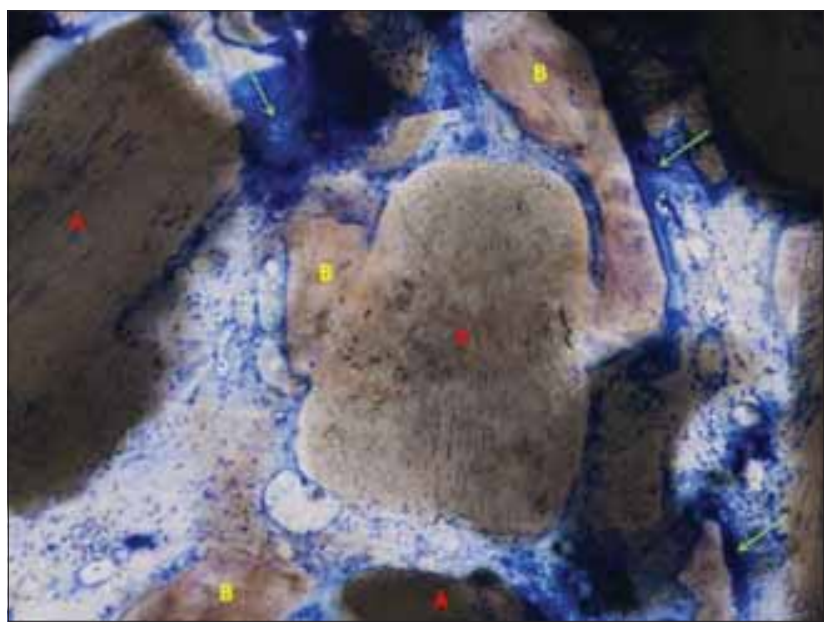

Figure 6: Algipore (A). N umerous phytoblocks were surrounded by connective tissue and by bone (B) trabeculae, that resulted with a high level of mineralization. Green arrows showed some areas of osteoid, rich in collagen and cells. Light microscope, total magnification $\times 100$, Toluidine Blue/Pyronin $Y$

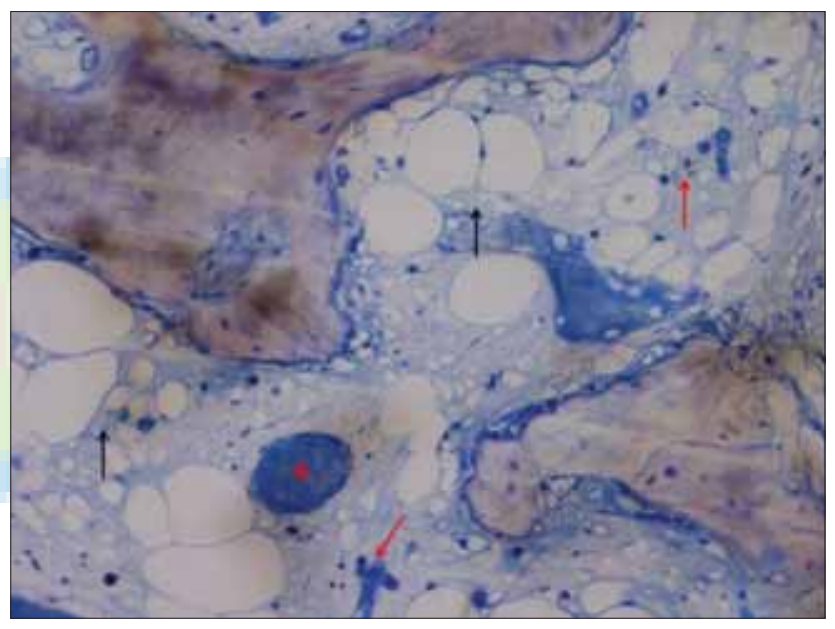

Figure 8: Algipore (A). Islands of newly formed bone immersed in a highly cellular medullary space. Adipocytes (black arrow) and a vascular network of blood vessels (red arrow) were present. Light microscope, total magnification $\times 200$, Toluidine Blue/Pyronin Y

\section{DISCUSSIO N}

The usefulness of sinus lift depends on the grafting material. ${ }^{[23,24]}$ Autogenous bone has been documented as the gold standard. If bone substitutes are used, the operation required for harvesting of bone autogenous could be eliminated. The bone substitutes have to be resorbed and completely replaced with newly formed bone.

Several studies reported the using of synthetic hydroxyapatite, ${ }^{[25]}$ bovine bone ${ }^{[26]}$ $\beta$-tricalcium-phosphate, ${ }^{[27]}$ freeze-dried demineralized bone ${ }^{[28]}$ or bioactive glass. ${ }^{[14]}$ Even though results in these 


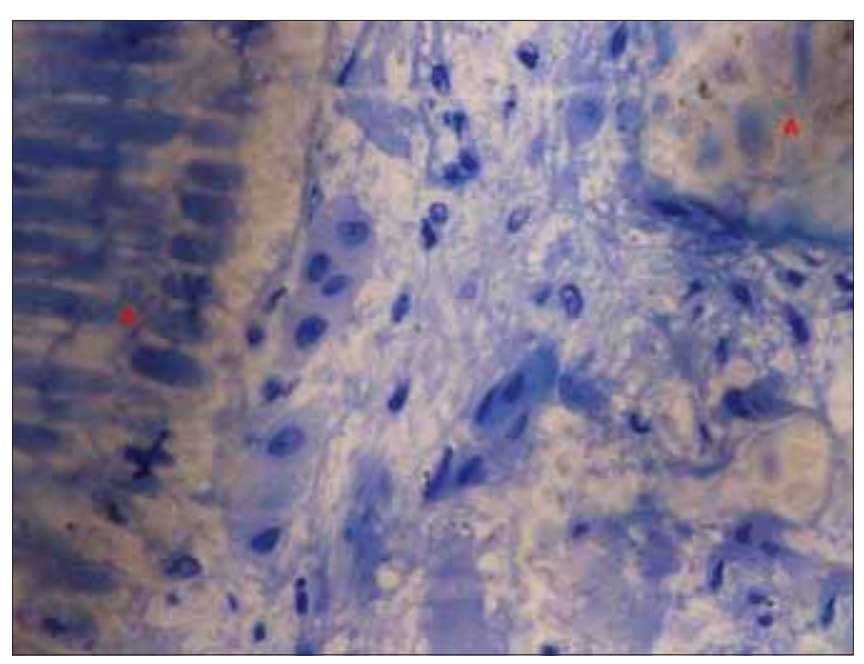

Figure 9: Algipore (A). Around biomaterial particles, numerous kinds of cells were detected. Many osteoblast-like cells and some precursors of osteoclasts were displayed close to Algipore blocks. Light microscope, total magnification $\times 600$, Toluidine Blue/Pyronin Y

publications were highly variable, it has been proven that the percentage of bone in the grafting material during the healing period grows and the percentage of unresorbed foreign residue is reduced. ${ }^{[28]}$

Actually we have a great number of studies, ${ }^{[29,30]}$ regarding the use of Bio-Oss in sinus grafting procedures, and we know how this material acts in terms of the osteoconduction, bone regeneration, biodegradation and volumetric stability of the graft. ${ }^{[31]}$

On the other hand, the general properties of the phytogenic bone substitutes Algipore have been researched by a number of authors. ${ }^{[15,17,32,33]}$ Algipore has been found to be a biocompatible, osteoconductive and resorbable biomaterial. ${ }^{[34]}$ Histological evaluation has shown that a tight contact between newly formed bone and biomaterial particles, without gaps or interposition of connective fibrous tissue was present. Porous biomaterials, such as Algipore, act as a scaffold for tissue regeneration. ${ }^{[15,17,33,35]}$ They guide cell and vessels migration into the pores. Cell and vessel movement inside the pores are related to the degree of interconnection of the pores and to its size. ${ }^{[15,17,33,35]}$ The degree of interconnection of the pores in Algipore, as well as the pore size, modulate cellular ingrowth in the material, allowing osteoconduction. ${ }^{[36]}$ Scarano et al. ${ }^{[17,32]}$ recently found that mineralized bone was present inside a large portion of the Algipore particles, which have a mean pore diameter of about 10 $\mu \mathrm{m}$. This fact is in contrast with other studies ${ }^{[18,37]}$ that stated that pores smaller than $10 \mu \mathrm{m}$ inhibit cellular ingrowth, while pores between $15 \mu \mathrm{m}$ and $50 \mu \mathrm{m}$ help fibrovascular colonization, pores between $50 \mu \mathrm{m}$ and $150 \mu \mathrm{m}$ determine osteoid growth, and pores larger than $150 \mu \mathrm{m}$ facilitate internal mineralized bone formation.
The growth of bone inside biomaterials particles could be related not only to pore size but, perhaps, also to the intrinsic characteristics of the biomaterial, opinion that was also stated by Schopper et al. ${ }^{[15]}$ Klongnoi et al. ${ }^{[38]}$ found, in a mini-pig study, that sinus augmentation with Algipore gave favorable results and that, after 12 months, the bone-to-implant contact percentage was very similar to that observed in augmented sinuses with autogenous bone. Wanschitz et al. ${ }^{[39]}$ found that in humans, after sinus augmentation with Algipore, the graft material showed a small volume loss during a 6-month period, providing a predictable volume for implant insertion.

Some authors demonstrated that the use of this biomaterial can trigger appositional bone formation in the maxillary sinuses of severely atrophic human maxillae even without additional bone harvesting. ${ }^{[15,17]}$ Schopper et al. found the average amount of bone that had formed after a mean healing time of 7 months was $23 \%{ }^{[15]}$ and this is in agreement with our investigation $(27.91 \% \pm 12.82 \%)$; furthermore on the other hand Bio-Oss amount of new bone was slightly greater (mean $39.09 \% \pm 10.42 \%$ ).

In this study, we decided to use a split-mouth design in order to compare the behavior of Algipore and Bio-Oss in the same patient from an histologic and histomorphometric point of view. Because of the split-mouth approach used, only a limited number of patients was enrolled in the study. In the present work, similar results were obtained compared with previous studies. ${ }^{[15,17]}$ The samples grafted with Algipore showed the same behavior as other studies considering the percentage of regenerated bone, residual biomaterial and medullary spaces. In bone remodeling process and in graft resorption, Algipore particles were gradually substituted by newly formed bone. ${ }^{[15,17]}$ The texture of Algipore serves as an osteoconductive scaffold for osteoblastic cells and stimulates deposition of bone matrix. ${ }^{[17]}$ In this study, we observed that after 6 months $43 \%$ of Algipore is still present, once again in line with the results obtained by Schopper after 7 months (33\% $\pm 7.8 \%)$ and by Scarano et al. after 6 months $(37.1 \% \pm 3.8 \%) .{ }^{[17]} \mathrm{We}$ know, from the previous study of Simunek et al. ${ }^{[33]}$ that Algipore is gradually resorbed and replaced by newly formed bone. During the time period of 6-15 months, the percentage of newly formed bone grows linearly, and the percentage of Algipore decreases linearly. After 15 months, the density of bone trabeculae in the grafted sinus corresponds to cancellous bone of good quality.

After 6 months of healing about $22 \%$ of residual Bio-Oss was found, and a higher presence of medullary spaces for Bio-Oss (38.61\% on average) than Algipore (29.22\% on average) was observed. We know from the previous study that this material is rapidly metabolized, but some particles are still present after many years. ${ }^{[40]}$ 
The results of the present study have shown that both biomaterials can be used with success in maxillary sinus augmentation procedures having good biocompatibility and osteoconductive properties, regenerated bone closed to the biomaterial surface and no histological signs of adverse reactions. Algipore and Bio-Oss seem to be gradually resorbed materials, partially substituted by newly formed bone. After 6 months, several residuals of biomaterials were found mostly in Algipore specimens. The slow resorption rate could be an advantage in that it helps in keeping the dimension of the augmented sinuses.

\section{CONCLUSION}

Within the limitations of the present study, the data confirmed that maxillary sinus lift carried out with Algipore performed in a similar way of that carried out with Bio-Oss and that this material is safe, predictable and without invasiveness.

\section{REFEREN CES}

1. Boyne PJ, James RA. Grafting of the maxillary sinus floor with autogenous marrow and bone. J O ral Surg 1980;38:613-6.

2. Tatum $\mathrm{H}$ Jr. Maxillary and sinus implant reconstructions. Dent Clin North Am 1986;30:207-29.

3. Merkx MA, Maltha JC, Stoelinga PJ. Assessment of the value of anorganic bone additives in sinus floor augmentation: A review of clinical reports. Int J O ral Maxillofac Surg 2003;32:1-6.

4. Wallace SS, Froum SJ. Effect of maxillary sinus augmentation on the survival of endosseous dental implants. A systematic review. Ann Periodontol 2003;8:328-43.

5. Del Fabbro M, Testori T, Francetti L, W einstein R. Systematic review of survival rates for implants placed in the grafted maxillary sinus. Int J Periodontics Restorative Dent 2004;24:565-77.

6. Emmerich D, Att W, Stappert C. Sinus floor elevation using osteotomes: A systematic review and meta-analysis. J Periodontol 2005;76:1237-51.

7. Hürzeler MB, Kirsch A, Ackermann KL, Quiñones $C R$. Reconstruction of the severely resorbed maxilla with dental implants in the augmented maxillary sinus: A 5-year clinical investigation. Int J O ral M axillofac Implants 1996;11:466-75.

8. N kenke $E$, Stelzle F. Clinical outcomes of sinus floor augmentation for implant placement using autogenous bone or bone substitutes: A systematic review. Clin O ral Implants Res 2009;20 Suppl 4:124-33.

9. Johansson B, Grepe A, W annfors K, H irsch JM. A clinical study of changes in the volume of bone grafts in the atrophic maxilla. Dentomaxillofac Radiol 2001;30:157-61.

10. M aiorana C, Sigurtà D, M irandola A, Garlini G, Santoro F. Bone resorption around dental implants placed in grafted sinuses: Clinical and radiologic follow-up after up to 4 years. Int J O ral Maxillofac Implants 2005;20:261-6.

11. Jensen OT, Shulman LB, Block MS, lacono VJ. Report of the Sinus Consensus Conference of 1996. Int J O ral Maxillofac Implants 1998;13 Suppl: 11-45.

12. Browaeys $H$, Bouvry $P$, De Bruyn $H$. A literature review on biomaterials in sinus augmentation procedures. Clin Implant Dent Relat Res 2007;9:166-77.
13. Jensen SS, Terheyden $\mathrm{H}$. Bone augmentation procedures in localized defects in the alveolar ridge: Clinical results with different bone grafts and bone-substitute materials. Int J 0 ral Maxillofac Implants 2009;24 Suppl: 218-36.

14. Cordioli G, Mazzocco C, Schepers E, Brugnolo E, Majzoub Z. $M$ axillary sinus floor augmentation using bioactive glass granules and autogenous bone with simultaneous implant placement. Clinical and histological findings. Clin O ral Implants Res 2001;12:270-8.

15. Schopper C, Moser D, Sabbas A, Lagogiannis G, Spassova E, König $F$, et al. The fluorohydroxyapatite (FHA) FRIOS Algipore is a suitable biomaterial for the reconstruction of severely atrophic human maxillae. Clin Oral Implants Res 2003;14:743-9.

16. Thorwarth M, W ehrhan F, Srour S, Schultze-Mosgau S, Felszeghy E, Bader RD, et al. Evaluation of substitutes for bone: Comparison of microradiographic and histological assessments. Br J O ral Maxillofac Surg 2007; 45:41-7.

17. Scarano A, Degidi M, Perrotti V, Piattelli A, Iezzi G. Sinus augmentation with phycogene hydroxyapatite: $\mathrm{H}$ istological and histomorphometrical results after 6 months in humans. A case series. O ral Maxillofac Surg 2012;16:41-5.

18. Hutmacher DW. Scaffolds in tissue engineering bone and cartilage. Biomaterials 2000;21:2529-43.

19. Cordaro L, Bosshardt DD, Palattella P, Rao W, Serino G, Chiapasco M. M axillary sinus grafting with Bio-O ss or Straumann Bone Ceramic: Histomorphometric results from a randomized controlled multicenter clinical trial. Clin O ral Implants Res 2008;19:796-803.

20. Chiapasco M, Casentini P, Zaniboni M. Bone augmentation procedures in implant dentistry. Int J O ral Maxillofac Implants 2009;24 Suppl: 237-59.

21. Arti Z, N emcovsky CE, D ayan D. Bovine-HA spongiosa blocks and immediate implant placement in sinus augmentation procedures. Histopathological and histomorphometric observations on different histological stainings in 10 consecutive patients. Clin O ral Implants Res 2002;13:420-7.

22. Donath $K$, Breuner $G$. A method for the study of undecalcified bones and teeth with attached soft tissues. The Säge-Schliff (sawing and grinding) technique. J O ral Pathol 1982;11:318-26.

23. Wheeler SL, Holmes RE, Calhoun CJ. Six-year clinical and histologic study of sinus-lift grafts. Int J O ral M axillofac Implants 1996;11:26-34.

24. Wheeler SL. Sinus augmentation for dental implants: The use of alloplastic materials. J O ral M axillofac Surg 1997;55:1287-93.

25. Arti Z, Nemcovsky CE, Tal H, Dayan D. Histopathological morphometric evaluation of 2 different hydroxyapatite-bone derivatives in sinus augmentation procedures: A comparative study in humans. J Periodontol 2001;72:911-20.

26. Valentini P, Abensur D, D ensari D, Graziani JN, Hämmerle C. Histological evaluation of Bio-O ss in a 2-stage sinus floor elevation and implantation procedure. A human case report. Clin O ral Implants Res 1998;9:59-64.

27. Szabó G, Suba Z, H rabák K, Barabás J, N émeth $Z$. Autogenous bone versus beta-tricalcium phosphate graft alone for bilateral sinus elevations (2-and 3-dimensional computed tomographic, histologic, and histomorphometric evaluations): Preliminary results. Int J O ral Maxillofac Implants 2001;16:681-92.

28. Landi L, Pretel RW Jr, Hakimi NM, Setayesh R. Maxillary sinus floor elevation using a combination of DFDBA and bovine-derived porous hydroxyapatite: A preliminary histologic and histomorphometric report. Int J Periodontics Restorative Dent 2000;20:574-83.

29. Jensen T, Schou S, Stavropoulos A, Terheyden H, H olmstrup P. 
Maxillary sinus floor augmentation with Bio-O ss or Bio-Oss mixed with autogenous bone as graft: A systematic review. Clin O ral Implants Res 2012;23:263-73.

30. Degidi M, Artese L, Rubini C, Perrotti V, lezzi G, Piattelli A. Microvessel density and vascular endothelial growth factor expression in sinus augmentation using Bio-O ss. Oral Dis 2006;12:469-75.

31. M aiorana C, Sigurtà D, M irandola A, G arlini G, Santoro F. Sinus elevation with alloplasts or xenogenic materials and implants: An up-to-4-year clinical and radiologic follow-up. Int J O ral Maxillofac Implants 2006;21:426-32.

32. Scarano A, Perrotti V, Degidi M, Piattelli A, Iezzi G. Bone regeneration with algae-derived hydroxyapatite: $A$ pilot histologic and histomorphometric study in rabbit tibia defects. Int J O ral M axillofac Implants 2012;27:336-40.

33. Simunek A, Cierny M, Kopecka D, Kohout A, Bukac J, Vahalova $D$. The sinus lift with phycogenic bone substitute. A histomorphometric study. Clin Oral Implants Res 2005; 16:342-8.

34. Iezzi G, D egidi M, Piattelli A, M angano C, Scarano A, Shibli JA, et al. Comparative histological results of different biomaterials used in sinus augmentation procedures: A human study at 6 months. Clin O ral Implants Res 2012;23:1369-76.

35. Ewers R, Goriwoda W, Schopper C, Moser D, Spassova E. $\mathrm{Histologic}$ findings at augmented bone areas supplied with two different bone substitute materials combined with sinus floor lifting. Report of one case. Clin O ral Implants Res 2004;15:96-100.
36. Schopper C, M oser D, W anschitz F, W atzinger F, Lagogiannis G, Spassova $E$, et al. Histomorphologic findings on human bone samples six months after bone augmentation of the maxillary sinus with Algipore. J Long Term Eff M ed Implants 1999;9:203-13.

37. Jones AC, Arns CH, Hutmacher DW , Milthorpe BK, Sheppard AP, Knackstedt MA. The correlation of pore morphology, interconnectivity and physical properties of 3D ceramic scaffolds with bone ingrowth. Biomaterials 2009;30:1440-51.

38. Klongnoi $B$, Rupprecht $S$, Kessler $P$, Zimmermann $R$, Thorwarth $M$, Pongsiri $S$, et al. Lack of beneficial effects of platelet-rich plasma on sinus augmentation using a fluorohydroxyapatite or autogenous bone: An explorative study. J Clin Periodontol 2006;33:500-9.

39. Wanschitz F, Figl M, W agner A, Rolf E. Measurement of volume changes after sinus floor augmentation with a phycogenic hydroxyapatite. Int J Oral Maxillofac Implants 2006;21:433-8.

40. Sartori S, Silvestri M, Forni F, Icaro CornagliaA, Tesei P, Cattaneo V. Ten-year follow-up in a maxillary sinus augmentation using anorganic bovine bone (Bio-O ss). A case report with histomorphometric evaluation. Clin O ral Implants Res 2003;14:369-72.

How to cite this article: Garlini G, Redemagni M, Canciani E, Dellavia C. Maxillary sinus floor augmentation with vegetal hydroxyapatite "versus" demineralized bovine bone: A randomized clinical study with a split-mouth design. J Dent Implant 2014;4:118-25.

Source of Support: Nil, Conflict of Interest: None.

Announcement

\section{“QUICK RESPONSE CODE” LINK FOR FULL TEXT ARTICLES}

The journal issue has a unique new feature for reaching to the journal's website without typing a single letter. Each article on its first page has a "Quick Response Code". Using any mobile or other hand-held device with camera and GPRS/other internet source, one can reach to the full text of that particular article on the journal's website. Start a QR-code reading software (see list of free applications from http://tinyurl.com/yzlh2tc) and point the camera to the QR-code printed in the journal. It will automatically take you to the HTML full text of that article. One can also use a desktop or laptop with web camera for similar functionality. See http://tinyurl.com/2bw7fn3 or http://tinyurl.com/3ysr3me for the free applications. 